\title{
Preparation, micro-structure and mechanical properties of porous carbonate apatite using chicken bone as raw material
}

\author{
Nguyen Xuan Thanh Tram ${ }^{1,2, *}$
}

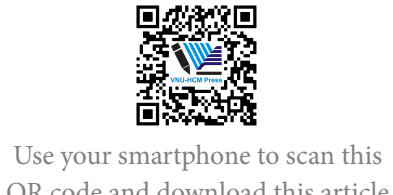

QR code and download this article
${ }^{1}$ Department of Silicate Materials, Faculty of Materials Technology, Ho Chi Minh City University of Technology, VNU-HCM, Ho Chi Minh City, Vietnam

${ }^{2}$ Department of Biomaterials, Faculty of Dental Science, Kyushu University,

Fukuoka, Japan

Correspondence

Nguyen Xuan Thanh Tram, Department of Silicate Materials, Faculty of Materials Technology, Ho Chi Minh City University of Technology, VNU-HCM, Ho Chi Minh City, Vietnam

Department of Biomaterials, Faculty of Dental Science, Kyushu University,

Fukuoka, Japan

Email:nxttram@hcmut.edu.vn

History

- Received: 2018-12-02

- Accepted: 2019-12-24

- Published: 2019-12-31

DOI : 10.32508/stdj.v22i4.1218

\section{Check for updates}

\section{Copyright}

(c) VNU-HCM Press. This is an openaccess article distributed under the terms of the Creative Commons Attribution 4.0 International license.

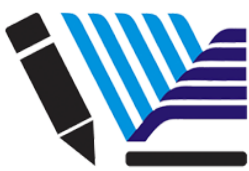

VNU-HCM Press

\begin{abstract}
Introduction: The increasing in bone loss due to trauma disease or accident leads to the demand for bone substitute materials. Autograft is the gold standard for bone graft; however, it has limited supplies and additional surgery for harvesting. Therefore, the artificial bone graft is necessary for bone defect treatment. One of the potential candidates for bone repair and regeneration is porous Carbonate Apatite $\left(\mathrm{CO}_{3} \mathrm{Ap}\right)$ due to its excellent biodegradability and biocompatibility. Understanding the importance of recycling of waste materials and by-products from the food industry such as poultry bone could be used as the alternative source for starting material. Thus, recycling and adding value for the food waste could be done with the development of artificial bone graft. Method: In this study, porous $\mathrm{CO}_{3} \mathrm{Ap}$ was prepared using bio apatite powder derived from chicken bone via the sacrificial template technique. Templates such as chopped cotton fibers were used to make porous $\mathrm{CO}_{3} \mathrm{Ap}$ with interconnecting pores. X-ray diffraction (XRD) and Scanning electron microscope (SEM) were used to characterize phase composition and structure. Carbonate content was evaluated using elemental analysis CHN (carbon hydrogen and nitrogen) analyzer. Results: The results indicated that a pure $\mathrm{CO}_{3} \mathrm{Ap}$ block consisting of elongating pores could be obtained. Mechanical strength was evaluated in terms of Diametral Tensile Strength (DTS). Porous $\mathrm{CO}_{3} \mathrm{Ap}$ had a mean DTS value of $198.5 \pm 12.9 \mathrm{kPa}$ and an average porosity of approximately $70 \%$. As a conclusion, $\mathrm{CO}_{3} \mathrm{Ap}$ containing $5.25 \pm 0.03 \%$ wt of carbonate with low crystallinity and the interconnecting porous structure is advantageous on bone regeneration as being a useful material for application to repair the bone defect.
\end{abstract}

Key words: Interconnected pores, Porous carbonate apatite, Sacrificial template

\section{INTRODUCTION}

During the last few decades, there is a tendency to an increase of cartilage and bone-related diseases, skeletal defects, tumor resection, skeletal abnormalities and bone fractures originating from trauma. Human bone can regenerate itself. However, this ability is reduced with time.

Moreover, the incomplete repair sometime occurred in case of significant defects. Although auto-graft is the gold standard for bone substitutes, it has many drawbacks such as limited supply, trauma and additional pain for patients. Therefore, the artificial bone graft is necessary to satisfy the demand for bone fracture treatment.

Currently, porous bioceramics have played an essential role in clinical application as bone substitute materials. One of the most popular topics focuses on interconnecting porous carbonate apatite due to its excellent biodegradability and biocompatibility.

Carbonate apatite $\left(\mathrm{CO}_{3} \mathrm{Ap}\right)$ has a composition similar to that of natural bone exhibiting good osteoconductive and osteogenic properties ${ }^{1-3} \cdot \mathrm{CO}_{3} \mathrm{Ap}$ as bone substitute materials for implant surgery could be granule, block or cement. Granule, block and cement could be prepared from $\mathrm{CO}_{3} \mathrm{Ap}$ powder. Several methods were conducted to synthesize $\mathrm{CO}_{3} \mathrm{Ap}$ powder such as precipitation, hydrothermal and mechanical activation ${ }^{4-10}$.

Besides, $\mathrm{CO}_{3} \mathrm{Ap}$ powder was also extracted from natural bone sources such as pig and cow bone or teeth, etc, This method is advantageous on economic and environmental benefits since it used the waste product of the food industry as the raw material ${ }^{11-13}$. Several methods were used to fabricate porous material from powder such as replica technique, direct foaming, etc.

In order to recycle and add value for the food waste, in this study, the chicken bone was collected and used as raw materials for fabrication bone substitute. The sacrificial template technique was used for preparing porous carbonate apatite $\left(\mathrm{CO}_{3} \mathrm{Ap}\right)$ due to its simplicity. Chopped cotton fibers are available in the form of long rods, and incorporation of these materials into a powder mix can produce interconnecting porosity. 


\section{MATERIALS AND METHOD}

\section{Preparation}

Chicken bone was collected from food waste. It was firstly removed the meat and fat residues, then rinsed with water. Bone was immersed in $2 \%$ sodium chloride ( $\mathrm{NaCl}, 7548-4100$, Daejung chemical \& metals Co. Ltd, Gyeonggi-do, Korea) solution for $2 \mathrm{~h}$ at $100^{\circ} \mathrm{C}$ for further removing of the other debris.

Bone was rinsed with distilled water and immersed in 2mol/L sodium hydroxide ( $\mathrm{NaOH}, 7571-4400$, Daejung chemical \& metals Co. Ltd, Gyeonggi-do, Korea) for $12 \mathrm{~h}$ at $80^{\circ} \mathrm{C}$.

Then, the bone was washed and filtered several times with distilled water using a vacuum bump until the filtrate was neutral.

The prepared bone was dried in the oven for $24 \mathrm{~h}$ and ground until as-prepared powder can pass through the $45-\mathrm{mm}$ sieve. Cotton fibers used as a sacrificial template were cut in $2-3 \mathrm{~mm}$ in length.

Chicken bone powder and cotton fibers were mixed to prepare powder mixture (7\% wt cotton fibers). The mixture was added with PVA (Polyvinyl alcohol 1500, 9002-89-5, Daejung chemical \& metals Co. Ltd, Gyeonggi-do, Korea) solution (5\% wt) as a binder to make a paste with the liquid to powder ratio $3: 2$.

The paste was packed into Teflon mold $(10 \mathrm{~mm} x$ $5 \mathrm{~mm})$. A mold was then placed inside the oven to dry at $100^{\circ} \mathrm{C}$ for $24 \mathrm{~h}$. After setting, mold was unpacked to obtain a composite block. The composite block was sintered at $600^{\circ} \mathrm{C}$ for $2 \mathrm{~h}$ under air for removing of cotton fiber. For as-prepared powder preparation, the experiment was repeated 3 times.

\section{Phase characterization}

The composition of the heat-treated composite block was done by means of powder X-ray diffraction (XRD) analysis.

After heat treatment, specimens were ground to fine powder, and the XRD patterns were recorded using a diffractometer system (D8 Advance, Bruker AXS $\mathrm{GmbH}$, Karlsruhe, Germany) using Vario1 Johansson focusing mono-chromator and high flux CuKa radiation generated at $40 \mathrm{kV}$ and $40 \mathrm{~mA}$. The specimens were scanned from $20^{\circ}$ to $60^{\circ} 2 \mathrm{q}$ (where $\mathrm{q}$ is the Bragg angle) in a continuous mode.

The carbonate content of the specimen was measured using the CHN coder (Yanako CHN coder. MT-6, Tokyo, Japan).

\section{Microstructure properties}

Morphology of the sintered specimen was observed by a Scanning Electron Microscope (SEM: S-3400N, Hitachi High-Technologies Co., Tokyo, Japan) at 10 $\mathrm{kV}$ of accelerating voltage after gold sputter coating.

Total porosity was estimated based on the measurement of volume and weight. The average value was calculated from the porosity value of 5 specimens.

\section{Mechanical properties}

Mechanical strength was evaluated in terms of Diametral Tensile Strength (DTS) using Universal Testing Machine (AGS-J, Shimadzu Corporation, Kyoto, Japan). The test was done with 5 specimens. The average DTS value was calculated from the DTS value of 5 specimens.

\section{RESULTS}

Figure 1 showed the XRD patterns of the composite block ( $7 \%$ wt cotton fibers) heating at $600^{\circ} \mathrm{C}$ for $2 \mathrm{~h}$. It can be seen that the pure apatite phase could be obtained and no secondary phase was detected. The XRD patterns showed the single phase of apatite, corresponding to the ICDD standard peak of stoichiometric hydroxyapatite (standard No.09-0432). It indicated that sintering at high temperatures resulted in the sharp and narrow diffraction peaks indicating high crystallinity. Sintering at elevated temperature was effective to remove completely cotton fiber as well as enhance the mechanical strength however the bioactivity of apatite would be reduced. In this case, sintering at $600^{\circ} \mathrm{C}$ was found to be suitable to eliminate the organic phase and maintain the low crystallinity.

Figure 2 showed the SEM image of the facture surface of the composite block (7\% wt cotton fibers) heating at $600^{\circ} \mathrm{C}$ for $2 \mathrm{~h}$. Macro-pores were obviously formed by burning out of the nylon fiber. After removing cotton fibers, the interconnecting porous structure could have appeared. Pores are interconnecting and in the form of long tunnels mimicking the morphology of cotton fiber.

Total porosity was estimated by measuring the bulk volume and weight of the heated block. Composite block with $7 \%$ wt cotton fibers was about $70 \%$ in total porosity after burning. Mechanical strength was evaluated in terms of Diametral Tensile Strength (DTS). Porous $\mathrm{CO}_{3}$ Ap had a mean DTS value of $198.5 \pm 12.9$ $\mathrm{kPa}$. 


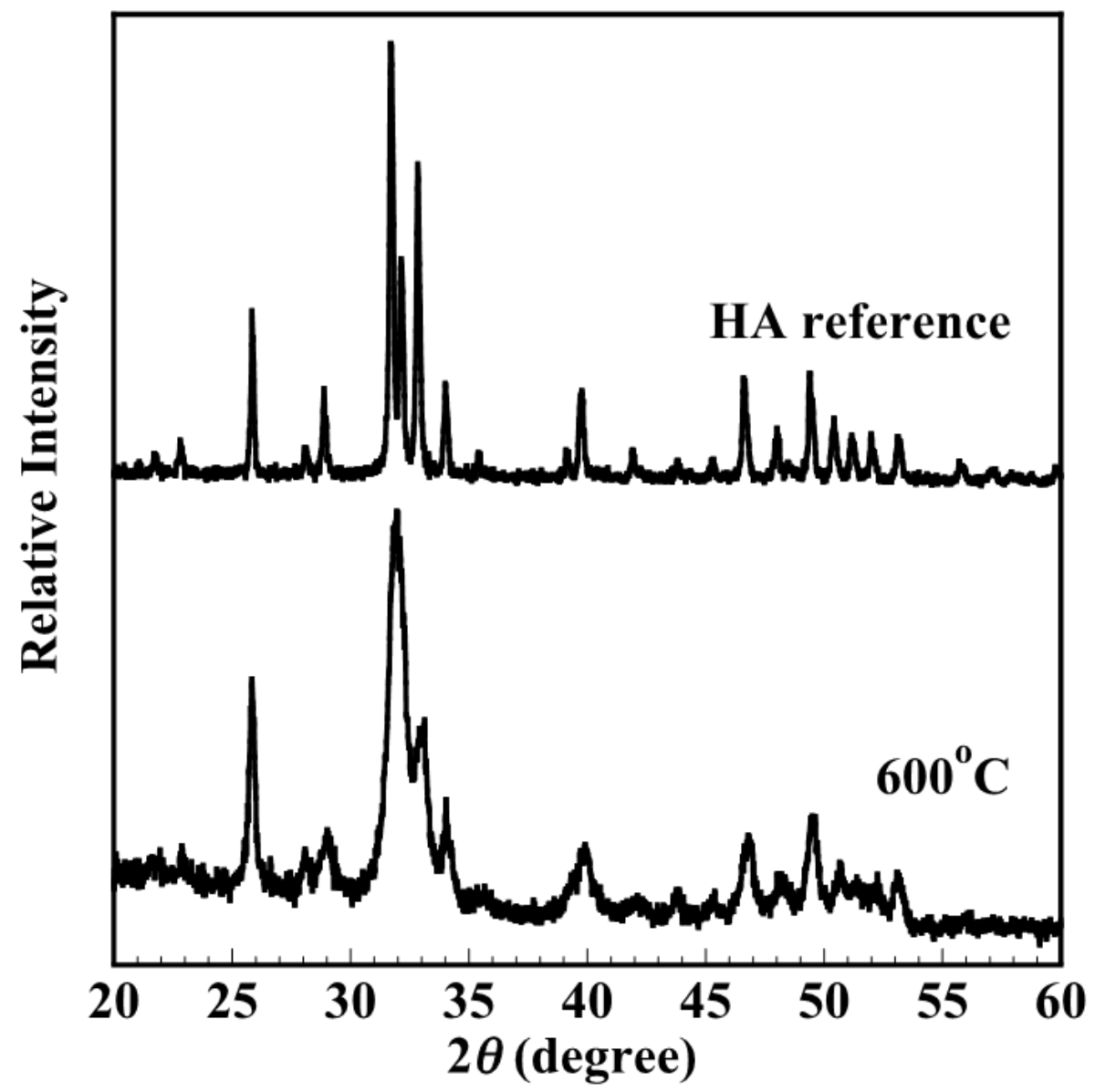

Figure 1: XRD patterns of the composite block ( $7 \%$ wt cotton fibers) obtained by sintering at $600^{\circ} \mathrm{C}$ for $2 \mathrm{~h}$ under air for removing of cotton fiber. XRD pattern indicated that all peaks belonging to the apatite phase (main apatite peak at 2theta $=26,32$ and 41 degrees).

\section{DISCUSSION}

Hence, the cotton fiber introduction was found to be effective for the formation of the porous structure. An interconnected porous network is an optimal environment for cell migration, proliferation and differentiation. Increasing of the interconnected pores supports extensive vascularization, rapid bone regeneration and good osteointegration ${ }^{14-19}$. It should be mentioned that porosity and mechanical strength have a trade-off relationship ${ }^{20-22}$. Therefore optimization of the porosity and mechanical strength is important for the clinical use of porous $\mathrm{CO}_{3} \mathrm{Ap}$.

Although the value of mechanical strength is not so high, specimen after sintering could fulfill the requirement of handling properties. This property is important since bone substitute materials need to be cut in the specific shape to fix the various shape of the bone defect.

The carbonate content of the specimen after sintering is $5.25 \pm 0.03 \% w t$. It indicated that this porous carbonate apatite block has a chemical composition similar to natural bone ${ }^{3}$. This could be advantageous on the biodegradable property ${ }^{2}$. By developing an artificial material with an appropriate threedimensional interconnected structure with good mechanical strength and biological functions, the recovery of bone defect and bone healing would be enhanced so that the patients could impede the suffering of bone fracture or other related chronic degenerative bone diseases. If the improved treatment for bone diseases was developed effectively, they could avoid the risk of disability. 


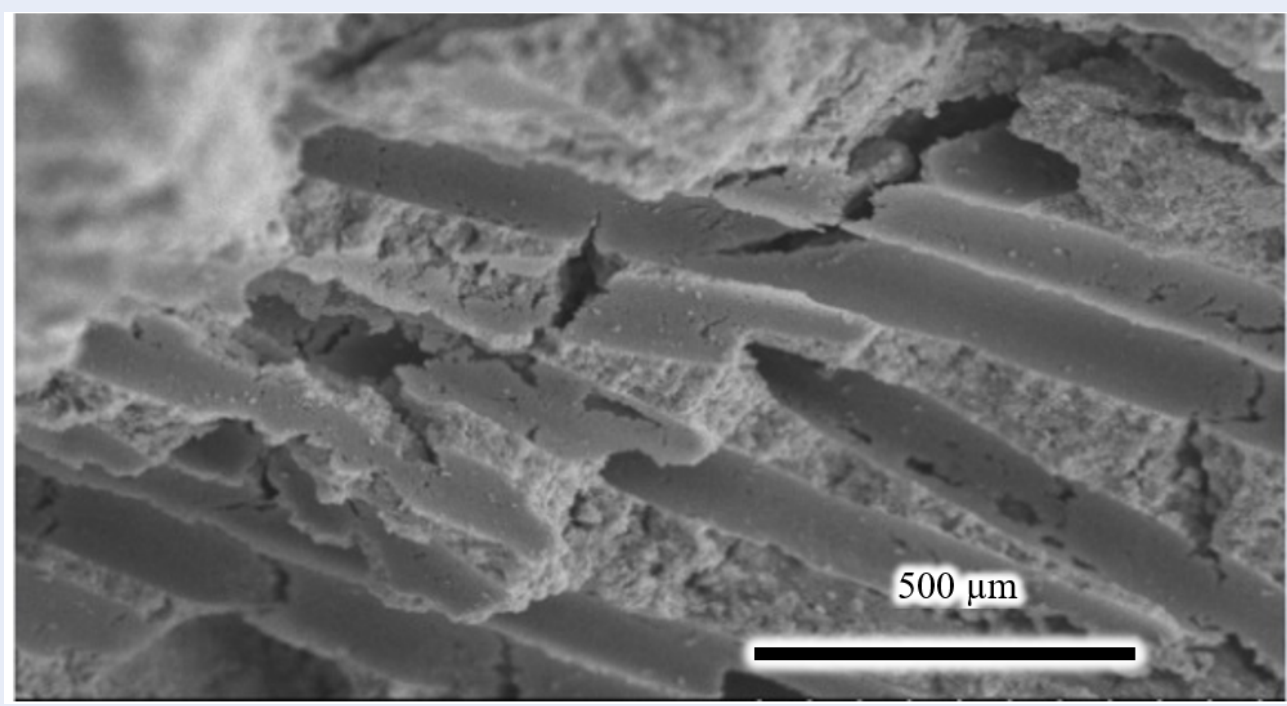

Figure 2: SEM image of the facture surface of the composite block ( $7 \%$ wt cotton fibers) obtained by sintering at $600^{\circ} \mathrm{C}$ for $2 \mathrm{~h}$ under air for removing of cotton fiber. The bioceramic contains pores distributing throughout its body. Micro-pores in the form of long tunnels presented at the fracture surface illustrating the interconnecting porous structure.

\section{CONCLUSIONS}

Solving the problem of waste is about value creation. In this study, a by-product of the food industry was useful for producing bone substitute materials. The results indicated that interconnecting porous carbonate apatite block could be fabricated using chicken bone powder/cotton fiber composite as starting materials. The specimen has fulfilled the requirement of handling property and has the same chemical composition as human bone. That means it could be advantageous with respect to use as bone substitutes. In the next research, in vitro and in vivo experiments need to be conducted to prove the biodegradable and biocompatible properties.

\section{COMPETING INTERESTS}

The authors declare that they have no conflicts of interest.

\section{ACKNOWLEDGMENT}

This research is funded by Ho Chi Minh City University of Technology - VNU- HCM, under grant number T-CNVL-2018-120. The author would like to thank the Department of Biomaterials, Faculty of Dental Science, Kyushu University and Faculty of Materials Technology, Ho Chi Minh City University of Technology, VNU-HCM for laboratory cooperation.

\section{REFERENCES}

1. Doi Y, Shibutani T, Moriwaki Y, Kajimoto T, Iwayama Y. Sintered carbonate apatites as bioresorbable bone substitutes.
Journal of Biomedical Materials Research. 1998;39(4):6030. Available from: 10.1002/(SICI)1097-4636(19980315)39: 4<603::AID-JBM15>3.0.CO;2-7.

2. Spence G, Patel N, Brooks R, Rushton N. Carbonate substituted hydroxyapatite: resorption by osteoclasts modifies the osteoblastic response. J Biomed Mater Res A. 2009;90(1):21724. PMID: 18496864 . Available from: $10.1002 / \mathrm{jbm} . \mathrm{a} .32083$.

3. Landi E, Celotti G, Logroscino G, Tampieri A. Carbonated hydroxyapatite as bone substitute. J Eur Ceram Soc. 2003;23(15):2931-7. Available from: 10.1016/S0955-2219(03) 00304-2.

4. Coreño AJ, Coreño AO, Cruz RJ, Rodríguez CC. Mechanochemical synthesis of nanocrystalline carbonate-substituted hydroxyapatite. Opt Mater. 2005;27(7):1281-5. Available from: 10.1016/j.optmat.2004.11.025.

5. Gibson IR, Bonfield W. Novel synthesis and characterization of an AB-type carbonate-substituted hydroxyapatite. J Biomed Mater Res. 2002;59(4):697-708. PMID: 11774332. Available from: $10.1002 / j b m .10044$.

6. Jokanović V, Izvonar D, Dramićanin MD, Jokanović B, Zivojinović $\mathrm{V}$, Marković $D$, et al. Hydrothermal synthesis and nanostructure of carbonated calcium hydroxyapatite. J Mater Sci Mater Med. 2006;17(6):539-46. PMID: 16691352. Available from: $10.1007 / \mathrm{s} 10856-006-8937-\mathrm{z}$.

7. Kovaleva ES, Shabanov MP, Putlayev VI, Filippov YY, Tretyakov YD, Ivanov VK. Carbonated hydroxyapatite nanopowders for preparation of bioresorbable materials. Materialwissenschaft und Werkstofftechnik: Entwicklung, Fertigung, Prüfung, Eigenschaften und Anwendungen technischer Werkstoffe. 2008;39(11):822-9. Available from: 10.1002/mawe. 200800383.

8. Lafon JP, Champion E, Bernache-Assollant D. Processing of AB-type carbonated hydroxyapatite Ca10- x (PO4) 6- x (CO3) $x(\mathrm{OH}) 2-\mathrm{x}-2 \mathrm{y}(\mathrm{CO} 3)$ y ceramics with controlled composition. J Eur Ceram Soc. 2008;28(1):139-47. Available from: 10.1016/j.jeurceramsoc.2007.06.009.

9. Landi E, Tampieri A, Celotti G, Vichi L, Sandri M. Influence of synthesis and sintering parameters on the characteristics of 
carbonate apatite. Biomaterials. 2004;25(10):1763-70. PMID: 14738839. Available from: 10.1016/j.biomaterials.2003.08.026.

10. Merry JC, Gibson IR, Best SM, Bonfield W. Synthesis and characterization of carbonate hydroxyapatite. J Mater Sci Mater Med. 1998;9(12):779-83. PMID: 15348939. Available from: 10.1023/A:1008975507498.

11. Figueiredo $M$, Fernando A, Martins $G$, Freitas J, Judas $F$ Figueiredo $\mathrm{H}$. Effect of the calcination temperature on the composition and microstructure of hydroxyapatite derived from human and animal bone. Ceram Int. 2010;36(8):238393. Available from: 10.1016/j.ceramint.2010.07.016.

12. Milovac D, Gamboa-Martínez TC, Ivankovic M, Ferrer GG, Ivankovic H. PCL-coated hydroxyapatite scaffold derived from cuttlefish bone: in vitro cell culture studies. Mater Sci Eng C 2014;42:264-72. PMID: 25063118. Available from: 10.1016/j. msec.2014.05.034.

13. Janus AM, Faryna M, Haberko K, Rakowska A, Panz T. Chemical and microstructural characterization of natural hydroxyapatite derived from pig bones. Mikrochim Acta. 2008;161(34):349-53. Available from: 10.1007/s00604-007-0864-2.

14. Wu SC, Tsou HK, Hsu HC, Hsu SK, Liou SP, Ho WF. A hydrothermal synthesis of eggshell and fruit waste extract to produce nanosized hydroxyapatite. Ceram Int. 2013;39(7):8183-8. Available from: 10.1016/j.ceramint.2013.03.094.

15. Gergely G, Wéber F, Lukács I, Tóth AL, Horváth ZE, Mihály J, et al. Preparation and characterization of hydroxyapatite from eggshell. Ceram Int. 2010;36(2):803-6. Available from: 10. 1016/j.ceramint.2009.09.020.

16. Galois $L$, Mainard D. Bone ingrowth into two porous ceramics with different pore sizes: an experimental study. Acta Orthop Belg. 2004;70(6):598-603. PMID: 15669463.
17. Gil-Albarova J, Vila M, Badiola-Vargas J, Sánchez-Salcedo $S$, Herrera A, Vallet-Regi M. In vivo osteointegration of three-dimensional crosslinked gelatin-coated hydroxyapatite foams. Acta Biomater. 2012;8(10):3777-83. PMID: 22728682 Available from: 10.1016/j.actbio.2012.06.019.

18. Will J, Melcher R, Treul C, Travitzky N, Kneser U, Polykandriotis $\mathrm{E}$, et al. Porous ceramic bone scaffolds for vascularized bone tissue regeneration. J Mater Sci Mater Med. 2008;19(8):278190. PMID: 18305907. Available from: 10.1007/s10856-0073346-5.

19. Mallick KK, Winnett J, van Grunsven W, Lapworth J, Reilly GC. Three-dimensional porous bioscaffolds for bone tissue regeneration: fabrication via adaptive foam reticulation and freeze casting techniques, characterization, and cell study. J Biomed Mater Res A. 2012;100(11):2948-59. PMID: 22696264. Available from: 10.1002/jbm.a.34238.

20. Munar ML. UDOH Kl, Ishikawa K, Matsuya S, Nakagawa M. Effects of sintering temperature over $1,300 \mathrm{C}$ on the physical and compositional properties of porous hydroxyapatite foam. Dent Mater J. 2006;25(1):51-8. PMID: 16706297. Available from: $10.4012 / \mathrm{dmj} .25 .51$.

21. Udoh K, Munar ML, Maruta M, Matsuya S, Ishikawa K. Effects of sintering temperature on physical and compositional properties of $\alpha$-tricalcium phosphate foam. Dent Mater J. 2010;29(2):154-9. PMID: 20379025. Available from: 10.4012/ dmj.2009-079.

22. Maruta M, Matsuya S, Nakamura S, Ishikawa K. Fabrication of low-crystalline carbonate apatite foam bone replacement based on phase transformation of calcite foam. Dent Mater J. 2011;30(1):14-20. PMID: 21282893. Available from: 10.4012/ dmj.2010-087. 